\title{
An Indian Cobra (Naja naja) Feeding on Hatchling Indian Rock Pythons (Python molurus)
}

\author{
Jaydeep Maheta ${ }^{1}$, Amit Sayyed ${ }^{2}$, Shruti Patel ${ }^{3}$, Rakesh Bharwad ${ }^{4}$, and Dinesh Prajapati ${ }^{5}$ \\ ${ }^{1}$ Wildlife Care Center, Ahmedabad Forest Department, Gujarat, India (jaydeep2305@gmail.com) \\ ${ }^{2}$ Wildlife Protection and Research Society, Maharashtra, India (amitsayyedsatara@gmail.com) \\ ${ }^{3}$ Wildlife and Conservation Biology Research Lab, Department of Life Sciences, Hemchandracharya North Gujarat University, Patan, Gujarat, India \\ ${ }^{4} \mathrm{Ab} / 1002$ Veer Savarkar Hights-2, Nr. Vasant Nagar Township, Ahmedabad, Gujarat, India \\ ${ }^{5}$ Sardarpura, Vadgam District, Banaskantha, Gujarat, India
}

$\mathrm{T}$ he Indian Cobra (Naja naja) is widely distributed in southern Asia and occurs almost nationwide in India, with the exception of high-elevation areas in Assam and parts of Kashmir (Daniel 2002). Whitaker and Captain (2004) stated that these snakes feed primarily on rodents, amphibians, lizards, other snakes, and small birds, and cannibalism has been reported. Unpublished observations made by wildlife rescuers have described $N$. naja feeding on chicken eggs in poultry farms and on newly born kittens. Herein we report an Indian Cobra feeding on a hatchling Indian Rock Python (Python molurus).

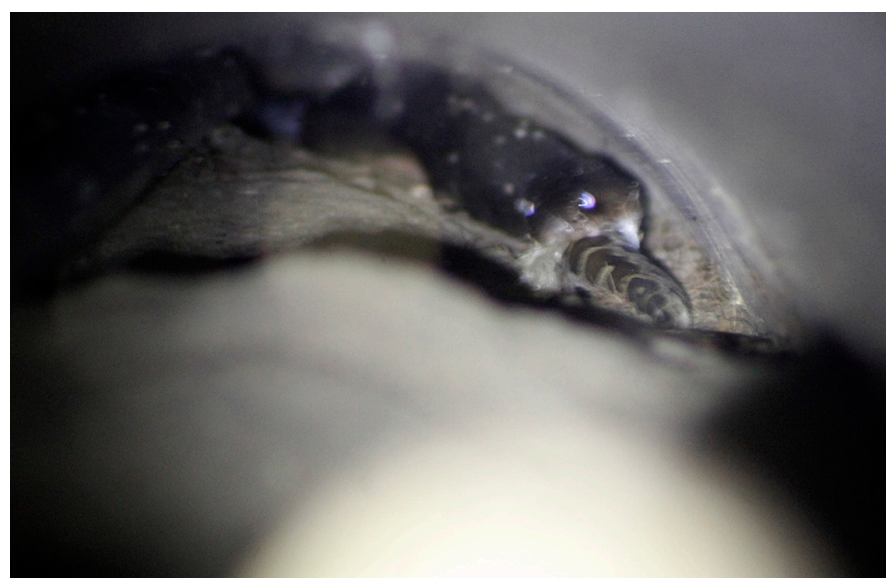

Fig. 1. An Indian Cobra (Naja naja) ingesting a hatchling Indian Rock Python (Python molurus). Photograph by Jaydeep Maheta.
In May 2019 we found eggs of an Indian Rock Python in a fallen pipe in the village of Khengariya, Ahmedabad District, Gujarat, India $\left(23.021614^{\circ} \mathrm{N}, 72.036949^{\circ} \mathrm{E}\right)$ and began monitoring the eggs without disturbing them. On 29 July 2019, we observed an Indian Cobra (ca. $2 \mathrm{~m}$ in total length) in the same pipe and set a video camera to monitor the snake's activity. During the night of 31 July, when hatchlings began emerging from the eggs, the cobra approached the eggs and ingested three hatchlings (Fig. 1). We cannot say whether the cobra waited for two days for hatchlings to emerge or whether the timing of this event was coincidental. To the best of our knowledge, this is the first report of an Indian Cobra feeding on hatchling Indian Rock Pythons.

\section{Acknowledgements}

We thank Uday Mehta, Rushi Pathak, Amishrimali, Elesh Mistry, Rohit Chhabaliya, Pravin Chhabaliya, Akshita Patel, and Payal Khichadiya for help in the field. We also are grateful to the Gujarat Forest Department and Range Forest Officer, Mr. D.J. Choudhari, for valuable support and guidance.

\section{Literature Cited}

Daniel, J.C. 2002. The Book of Indian Reptiles and Amphibians. Bombay Natural History Society and Oxford University Press, Oxford, England.

Mukherjee, A.K. 2012. Green medicine as a harmonizing tool to antivenom therapy for the clinical management of snakebite: The road ahead. Indian Journal of Medical Research 136: 10-12.

Whitaker, R. and A. Captain. 2004. Snakes of India. The Field Guide. Draco Books, Chennai, India. 